\title{
Composición y dinámica del empleo en Santiago del Estero 1994-2007
}

\section{Composition and dynamics of employment in Santiago del Estero 1994-2007}

\author{
María Noelia Gurmendi noegurmendi@gmail.com \\ https://orcid.org/0000-0001-5140-8127 \\ Instituto para el Desarrollo Social; Universidad Nacional de Santiago del Estero/ Consejo \\ Nacional de Investigaciones Científicas y Técnicas (Argentina)
}

Rita Gabriela Salvatierra rita.g.salvatierra@gmail.com https://orcid.org/0000-0002-6703-0920

Centro de Estudios de Demografía y Población; Universidad Nacional del Santiago del Estero/ Consejo Nacional de Investigaciones Científicas y Técnicas (Argentina) 
María Noelia Gurmendi y Rita Gabriela Salvatierra Composición y dinámica del empleo en Santiago del Estero 19942007

\section{Resumen}

La provincia de Santiago del Estero constituye dentro del país, una región con un peso marginal en la economía nacional ( $0,8 \%$ del PBI del país). Se caracteriza por un secular rezago productivo, con una estructura productiva con escasa participación industrial, lo que se traduce en un débil mercado de trabajo y en un deterioro social que afecta a un porcentaje importante de la población.

En esta investigación se analiza el mercado de trabajo de los sectores productores de bienes y de servicios, los cuales exhiben particularidades y relaciones que ameritan una explicación científica. Nuestro propósito reposa en develar los vínculos que estos mismos establecen, utilizando el PBG (Producto Bruto Geográfico) (1) para Santiago del Estero, como indicador macroeconómico principal, explicando la lógica y dinámica con que se movilizan los recursos entre los sectores a la luz de la teoría.

Palabras clave: empleo; categorías ocupacionales; institucionalidad.

\section{Abstract}

The province of Santiago del Estero constitutes within the country, a region with a marginal weight in the national economy $(0.8 \%$ of the country's GDP). It is characterized by a secular productive backwardness, with a productive structure with little industrial participation, which translates into a weak labor market and a social deterioration that affects a significant percentage of the population.

This research analyzes the labor market of the sectors producing goods and services, which exhibit particularities and relationships that merit a scientific explanation. Our purpose lies in unveiling the links they establish, using the PBG (Gross Geographical Product) for Santiago del Estero, as the main macroeconomic indicator, explaining the logic and dynamics with which resources are mobilized between sectors in light of the theory.

Keywords: employment; occupational categories; institutionality. 
María Noelia Gurmendi y Rita Gabriela Salvatierra Composición y dinámica del empleo en Santiago del Estero 19942007

\section{Introducción}

El mercado de trabajo ha sufrido la fuerte volatilidad de la economía en los últimos decenios. El proceso de globalización produjo impactos diversos de acuerdo a las regiones. En Latinoamérica, el neoliberalismo impuso cambios estructurales en las distintas economías (apertura económica, desregulación de los mercados y liberalización financiera, reducción del rol del Estado en la economía, entre otros), los que provocaron la quiebra de un número creciente de pequeños y medianos productores, comercios e industrias, ocasionando a su vez un incremento de la desocupación y subocupación, al igual que de la precariedad laboral y el empleo informal. La Argentina fue una de las naciones más afectadas por estos procesos. El período de los ' 90 produjo un proceso de desinstitucionalización del mercado de trabajo, que agravó su heterogeneidad. (2) El derrumbe de la economía en los años de la última gran recesión económica (1998-2002), llevó a niveles históricos las cifras de precariedad laboral, desempleo y subocupación.

El período siguiente, de la post-convertibilidad, implicó una intensa recuperación de diferentes sectores productivos, en el marco de una estabilidad macroeconómica que se extiende hasta 2007. Si bien la mega devaluación del año 2002, generó una notoria transferencia de recursos del sector servicios al sector de bienes transables (3), en pocos años las actividades servicios volvieron a tener un crecimiento importante. A su vez, esta dinámica económica permitió una relativa mejora del salario real (4) y una gradual tendencia a la institucionalización del empleo. Sin embargo, en el balance de la década se observa la persistencia de serios problemas en el mercado de trabajo, con una marcada heterogeneidad estructural entre e intra sectores y una recurrente segmentación de las categorías ocupacionales de la fuerza de trabajo. La provincia de Santiago del Estero constituye dentro del país, como una región marginal del capitalismo periférico, la cual se caracteriza por frágil sector industrial que nunca ha alcanzado niveles, ni cualidades adecuadas para propiciar el aumento sostenido de la productividad y el empleo, lo que se traduce en un débil mercado de trabajo, y en un deterioro social que afecta a un porcentaje importante de la población.

En este contexto, ciertos rasgos han caracterizado el mercado de trabajo en la provincia, tales como: 1) bajas tasas de participación laboral, 2) desde el punto de vista de la distribución sectorial del empleo, concentración de la ocupación en el sector agropecuario y en actividades de escaso dinamismo del sector terciario, con acento en los sectores de la administración pública, enseñanza, salud y comercio, 3) baja asalarización de la fuerza de trabajo y significativa importancia de la categoría del trabajo familiar en la agricultura, 4) relevancia en el nivel urbano del sector informal, el sobreempleo público y el servicio doméstico, 5) ocupación

Question, Vol. 1, N. ${ }^{\circ}$ 64, octubre-diciembre 2019. ISSN 1669-6581

Instituto de Investigaciones en Comunicación | Facultad de Periodismo y Comunicación Social | Universidad Nacional de La Plata La Plata | Buenos Aires | Argentina

Página 3 de 22 
en el nivel rural en actividades de subsistencia y/o de muy baja productividad, 6) una mínima productividad en los sectores transables respecto a los valores medios del país, y 7) una insuficiente participación del sector industrial como generador de empleo (Forni, 1979 y 1981; Zurita, 2000 y Tasso y Zurita, 2012, Silveti, 2017). Por lo expuesto, es menester resaltar que el mercado de trabajo santiagueño posee una considerable segmentación básicamente en términos diferenciales de ingreso, productividad y niveles de ocupación que por supuesto conllevan a generar grandes diferencias en la estructura y funcionamiento del empleo (Forni Floreal, 1991 p.51).

\section{La Dinámica del empleo entre sectores en Santiago del Estero}

Las evidencias empíricas del mercado de trabajo santiagueño nos develan que el territorio provincial puede caracterizarse como una región dual y económicamente deprimida, con sectores productores de bienes (5) que se retraen y expulsan trabajadores, contrariamente a los sectores de servicios donde se advierte un engrosamiento de mano obra que no ha sido absorbida por el sector industrial. Desde la etapa del proceso de industrialización por sustitución de importaciones (ISI) iniciada en el país durante la crisis del capitalismo en el S. XX (1929), las producciones agropecuarias se mantuvieron al margen del dinamismo productivo interno (6), mientras que la industria sustitutiva se afianzaba como el motor de la economía nacional. Cuando este proceso de industrialización se vio estancado (a mediados del siglo XX), indefectiblemente se produjo una terciarización sustitutiva (7).

Frente a este contexto la provincia reproduce el comportamiento expansivo del empleo público y de un relativo aislamiento de la economía local, advirtiéndose un sector agrícola expulsor de mano de obra, un sector industrial que no alcanzó niveles adecuados de crecimiento para impulsar el aumento sostenido de la productividad y generación de puestos de trabajo, y un sector terciario que se instauró como un receptor de empleos de muy baja productividad y formalidad. 


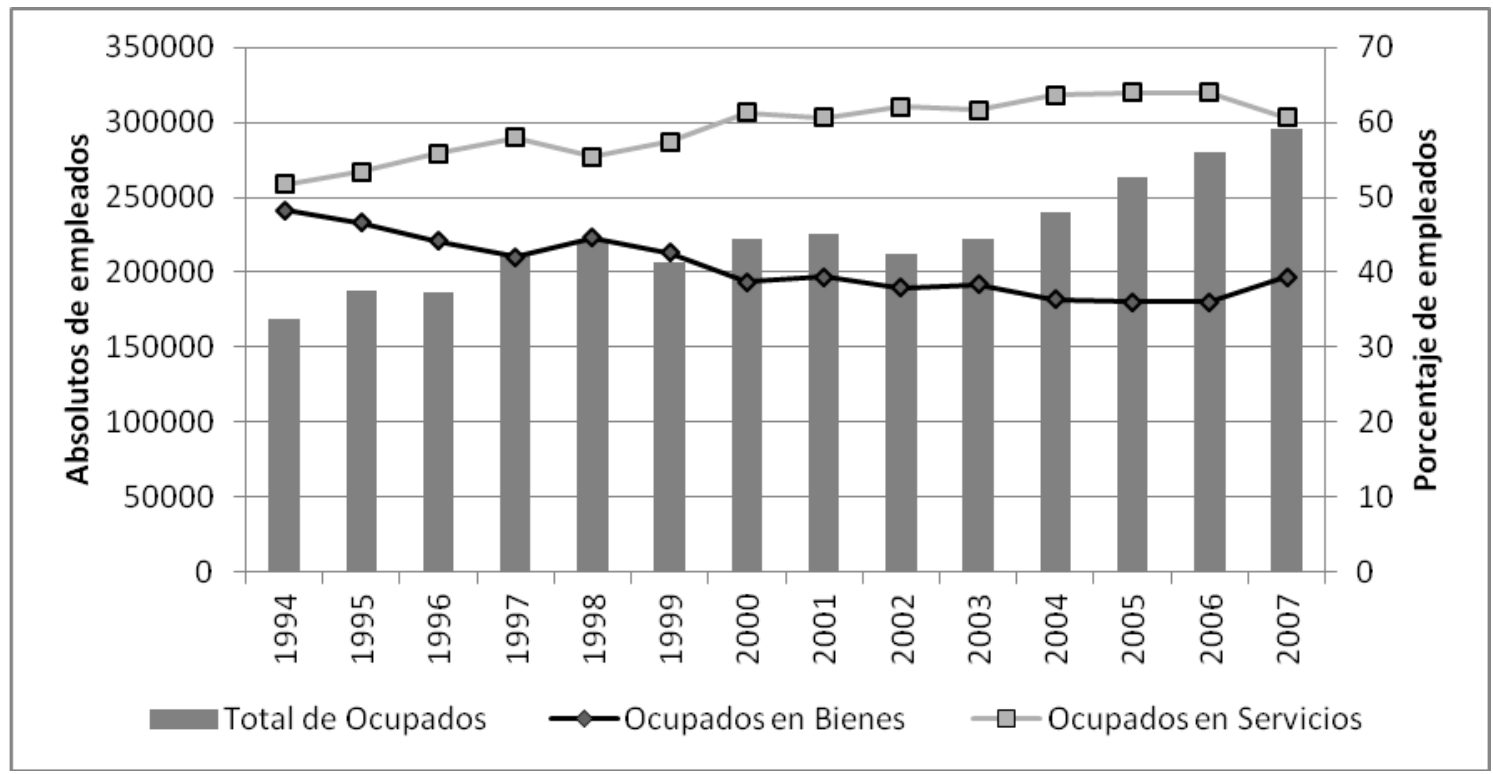

Gráfico №1: Evolución del empleo en los sectores productores de bienes y servicios

Fuente: PBP, CFI, 2008. Elaboración propia.

Como se observa en el Gráfico 1, la dinámica del empleo entre el 1994 y 2007se mantiene en alza en el sector servicios oscilando entre el $50 \%$ y $70 \%$ de la mano de obra inserta en dicho sector, mientras que en menor medida el sector productor de bienes pierde paulatinamente puestos de trabajo, iniciándose para el año 1994 con el 50\% hasta culminar la serie en estudio (2007) con un $40 \%$. Si bien Santiago del Estero constituye una provincia que se caracteriza por elevado nivel de atraso, bajo un proceso de limitada modernización, evidenciando heterogeneidad económica, productiva y laboral. Se destaca que el sector servicios, si bien tuvo una fase recesiva entre 1994/1996, su tendencia se enmarca en un crecimiento sostenido del empleo en detrimento del sector de bienes. Esto se explica porque mientras el sector de bienes se contrae en sintonía con la fase de recesión del periodo de convertibilidad, el sector servicios, en términos cepalinos, constituye un ajuste defensivo que viene paliar la expulsión de empleo del sector tradicional sustituyendo a la actividades modernas, urbanas e industriales (de acuerdo al modelo lewisiano) y constituyéndose, como consecuencia de dicho proceso, en un mercado de trabajo donde predominan un conjunto de actividades de servicios de precaria productividad, baja especialización y el surgimiento de una nueva forma de subsistencia informal (8).

Se advierte que la participación protagónica del empleo en servicios se encuentra sostenido por el comercio $(G)$ con un 24,5\%, administración pública (L) 17,5\%, enseñanza (M) $15,8 \%$, servicio doméstico $(\mathrm{P})$ 12,5\% y en menor medida salud $(\mathrm{N})$ 8,5\% a lo largo del periodo en 
María Noelia Gurmendi y Rita Gabriela Salvatierra Composición y dinámica del empleo en Santiago del Estero 19942007

estudio. Se debe tener en cuenta que tanto los sectores $L, M, N$ refieren al empleo público que le atañe al Estado, teniendo en cuenta que la salud se bifurca entre lo público y lo privado.

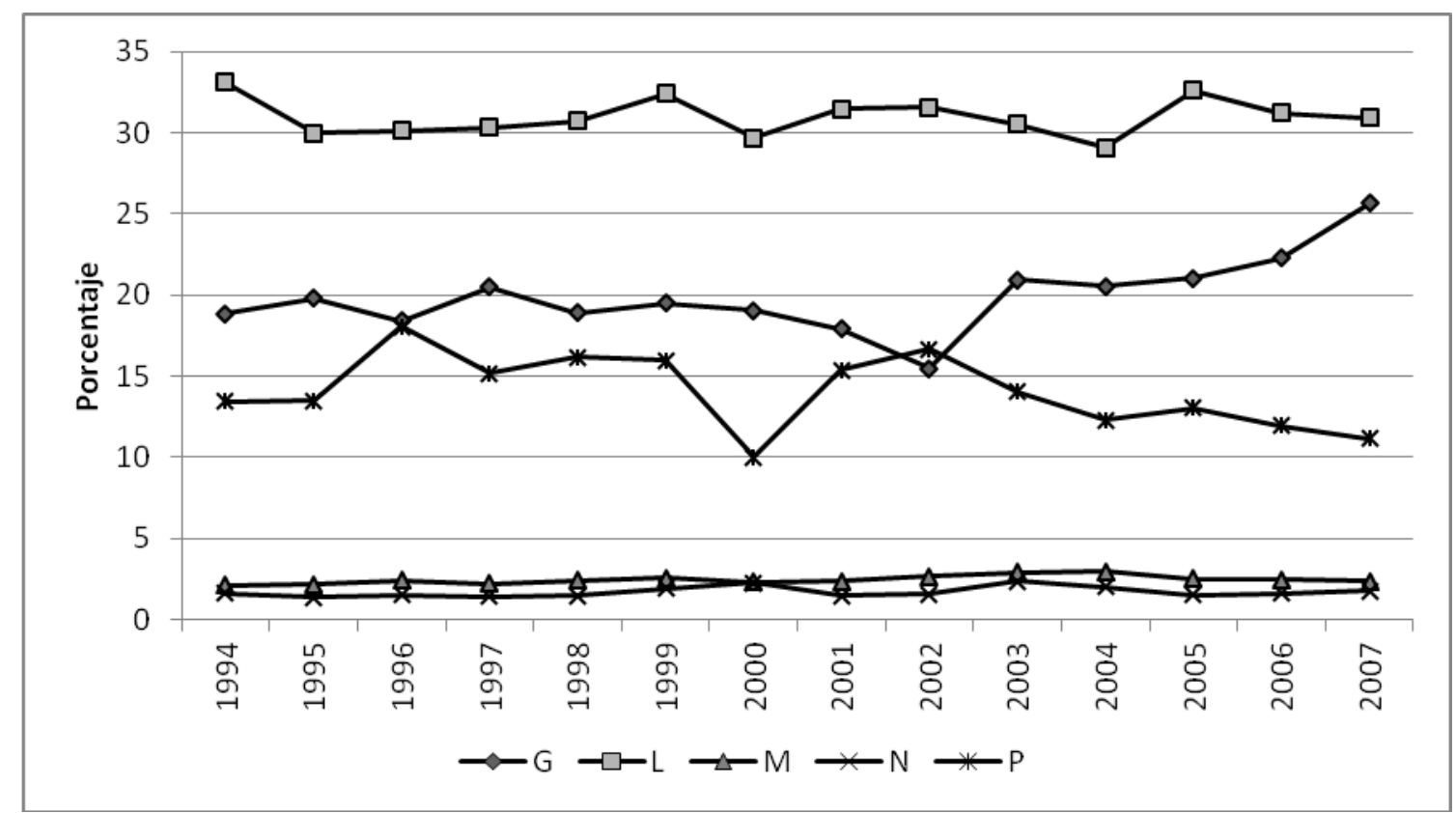

Gráfico №2: Evolución del empleo en los sectores productores de servicios. Fuente: PBP, CFI, 2008. Elaboración propia

Si observamos el grafico 2 la explicación de la dinámica del empleo se puede sustentar en los ciclos de la economía nacional. Sin embargo, la primera apreciación que se observa es la predominancia del sector $\mathrm{L}$ (administración pública y defensa) manteniéndose alrededor del $30 \%$ en todo el período, siendo muy poco afectado por la tendencia de los ciclos macroeconómicos. De modo contrario el sector $\mathrm{G}$ (comercio) tiene dos tendencias diferentes en toda la serie; la primera responde al ciclo del modelo de la convertibilidad entre 1994/2002 oscilando entre el $18 \%$ y $15 \%$, mientras que la segunda responde a la fase de recuperación económica post-convertibilidad a partir de 2003-2007 teniendo un comportamiento positivo entre el $20 \%$ y $25 \%$, siendo el segundo sector más relevante en la serie.

Punto aparte merece una fina interpretación la dinámica que tuvo el sector de Servicio doméstico $(P)$, ya que su comportamiento tiene una tendencia positiva entre 1994-1996 que llega al $20 \%$, para luego ir descendiendo, de forma paralela a la fase recesiva de la convertibilidad, culminando en un $10 \%$ para el año 2002. Con el cambio de modelo, su trayectoria cambia de manera positiva entre 2001/02 llegando al 15\%, para luego tener una tendencia relativamente estable entre el $10 \%$ y $13 \%$, marcando un comportamiento muy volátil en respuesta a los ciclos económicos. Por último, cabe destacar que este sector representa el 
María Noelia Gurmendi y Rita Gabriela Salvatierra Composición y dinámica del empleo en Santiago del Estero 19942007

tercer puesto en el ranking de la estructura ocupacional del empleo en servicios, siendo una característica principal la exigua calificación y baja productividad de su fuerza laboral.

Finalmente podemos resaltar que la dinámica del empleo en los servicios no responde a un crecimiento amparado en actividades dinamizadoras de la economía, como la industria, sino que resulta una alternativa forzada ante el contexto laboral desfavorable presionado por el sector tradicional de producción de bienes.

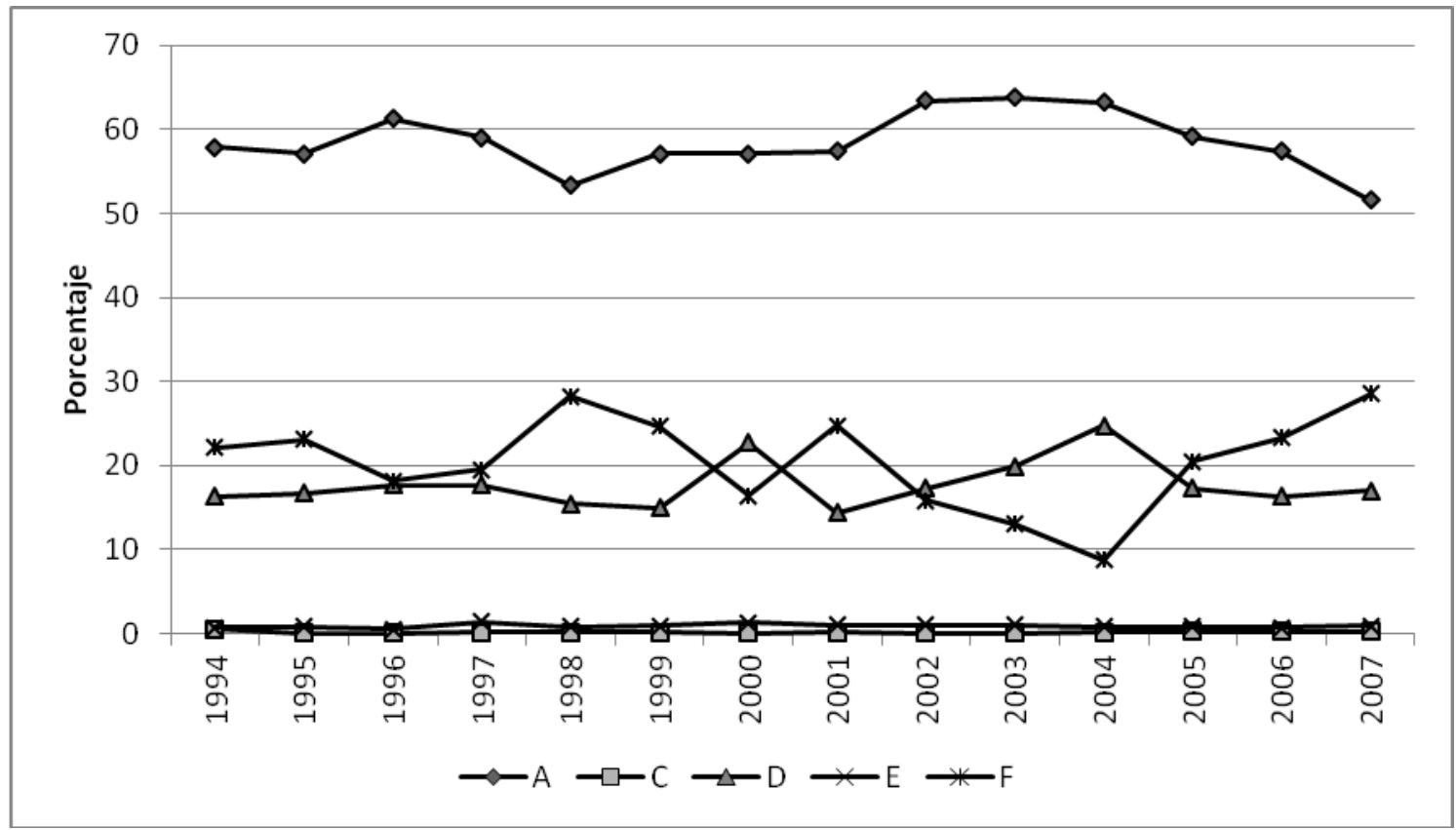

Gráfico №3: Evolución del empleo en los sectores productores de bienes. Fuente: PBP, CFI, 2008. Elaboración propia

En el análisis pormenorizado del sector productor de bienes, se observa en el gráfico № 3 que el sector (A) representa más del $50 \%$ del empleo de todos los sectores de bienes a final del período estudiado. Este sector crece en generación de empleo entre 1994-1996 para luego entrar en una fase de contracción que podría explicarse por el proceso de modernización que tiene como principal factor la incorporación de tecnologías que mejoraron los rendimientos disminuyendo los costos de producción entre 1997 y 2000. A partir del fin de la política de convertibilidad, con un nuevo tipo de cambio, el sector (A), específicamente las actividades agrícolas, comienza una fase de expansión con el objetivo de responder a la demanda del mercado externo de los bienes básicos en el marco de un proceso de reprimarización de la pauta exportadora a nivel nacional. Al mismo tiempo, la tendencia expansiva del empleo de este sector, durante el 2001 en adelante, se complementaría con el aumento de otras actividades agropecuarias destinadas al mercado interno nacional y provincial. Esta dinámica puede explicarse por la incorporación de innovaciones tecnológicas en paralelo a la demanda 
María Noelia Gurmendi y Rita Gabriela Salvatierra Composición y dinámica del empleo en Santiago del Estero 1994 2007

externa de bienes primarios que acentuaron la dualidad (9) productiva profundizando la heterogeneidad estructural del sector.

La expulsión de mano de obra del sector $(A)$ en la fase de contracción antes mencionada, probablemente tuvo dos vías de absorción en otras actividades; una de ellas responde a la explicación de la tercerización en las actividades de servicios, mientras que la otra podría estar vinculada a las actividades del sector de la construcción (F), las cuales a partir de 1997 en adelante expone una tendencia positiva en la generación de empleo por encima del 20\%, a pesar de las oscilaciones relativas a la fase recesiva del ciclo económico, que culmina con un $30 \%$ a final del período en estudio.

Sin embargo, el sector de industria manufacturera (D), como productor de bienes, refuerza las explicaciones realizadas ut-supra, ya que su comportamiento experimentó variaciones que no superaron el $20 \%$ de la mano de obra en todo el período, con la excepción de los años 20002004 que trepo el empleo hasta un 25\% aproximadamente. Esto nos conduce a confirmar que el sector nunca logro un proceso de industrialización sostenido en el tiempo que posibilitara la modernización (en términos lewisianos) de la sociedad reflejado en su mercado de trabajo. Esta situación de rezago productivo del sector (D) puede explicarse por diversos factores; desde el punto de vista productivo es preciso remarcar que no estamos en presencia de un sector dominante en la economía santiagueña, y mucho menos si tenemos en cuenta la poca presencia de unidades productivas de mayor tamaño (economías de escala interna), intensivas en trabajo barato no calificado (como el rubro textil), intensiva en recursos naturales abundantes en la geografía local (como la industria maderera, alimentos y bebidas), sin poder generar un espacio de apertura a la inversión en ramas más dinámicas vinculadas a la tecnología y a los bienes de alta elasticidad ingreso de la demanda, que incide en la mayor o menor posibilidad de aprovechamiento de economías de escala externas (o externalidades) y que sólo está orientado a satisfacer un mercado interno de reducida escala.

\section{Empleo e institucionalidad laboral en relación a las categorías ocupacionales}

El empleo es un eje ordenador de la estructura social, y como tal representa (en términos extensivos al mundo del trabajo) "la llave maestra" (10) para el desarrollo y la igualdad; sin embargo, la experiencia en sociedades subdesarrolladas, como las latinoamericanas, demuestra que no siempre se da una relación virtuosa entre la estructura productivaocupacional y la tendencia de los ciclos macroeconómicos en mayores oportunidades, capacidades e igualdad o convergencia de ingresos. La literatura de la que nos apropiamos para elucidar tentativamente algunas explicaciones a estos procesos se enmarca en el 
María Noelia Gurmendi y Rita Gabriela Salvatierra Composición y dinámica del empleo en Santiago del Estero 19942007

problema de la heterogeneidad estructural del mercado de trabajo, como un nudo gordiano, que pone de manifiesto la elevada incidencia del empleo informal (11) y la baja proporción de la población protegida por la seguridad social desde el ámbito laboral, como uno de los principales factores de la mala distribución del ingreso que genera profundas desigualdades sociales.

La institucionalidad del mercado de trabajo es fundamental para crear condiciones que permitan absorber los incrementos de la productividad gestados por un nuevo paradigma tecnológico y traducirlos en aumentos reales de salarios, reducción de las jornadas laborales y acceso a la protección social a un ritmo consistente con el itinerario de la eficiencia productiva intersectorial. Las políticas públicas de empleo son el puente entre las políticas sociales y las productivas, donde la intervención del Estado desempeña un papel central. Además, los gastos públicos en su conjunto tienen un fuerte efecto estabilizador de los ciclos económicos, ya que reducen las fluctuaciones del nivel de ingreso y de empleo y, de este modo, protegen a la población vulnerable en tiempos de crisis (Silveti, 2017).

Cabe resaltar que la institucionalidad laboral de acuerdo a la CEPAL (2014) incluye: 1) Seguridad de ingresos: nivel del salario, mecanismos de pago y ayudas económicas por desempleo; y fijación de salario mínimo, incluido el sector informal urbano (SIU) 2) Seguridad del mercado de trabajo: nivel de ocupación compatible con el pleno empleo. 3) Seguridad del empleo: permanentes, protegidos y de tiempo completo. Estimular la institucionalidad al sector de microempresas, a los hogares con servicio doméstico, a los trabajadores subcontratados y a domicilio, con menores cargas contributivas a la seguridad social, en conjunto con planes de fomento que limiten el costo de la formalización, que amortigüen los mayores costos de la formalidad: impuestos, patentes, etc., evitando descuidar la gestión de inspección y control. 4) Seguridad del trabajo: medidas precautorias para evitar enfermedades y accidentes.

De acuerdo al Producto Bruto Geográfico (PBG), se utiliza las categorías ocupacionales como nomenclatura para clasificar los puestos de trabajo que se dividen en: Asalariados: Existe una relación entre el empleador y el asalariado cuando hay un acuerdo, que puede ser formal o informal (registrado o no), entre una organización y una persona, normalmente voluntario para ambas partes, en virtud del cual la persona trabaja para el empleador a cambio de una remuneración en dinero o en especie. Trabajadores por cuenta propia: Son los trabajadores autónomos que no tienen empleados remunerados a su cargo. Empleadores/Patrones: Son los trabajadores autónomos que tienen empleados remunerados a su cargo. Familiares no remunerados: Son los trabajadores que colaboran en negocios familiares sin recibir un pago directo por su trabajo.

Question, Vol. 1, N. ${ }^{\circ}$ 64, octubre-diciembre 2019. ISSN 1669-6581

Instituto de Investigaciones en Comunicación | Facultad de Periodismo y Comunicación Social | Universidad Nacional de La Plata La Plata | Buenos Aires | Argentina

Página 9 de 22 


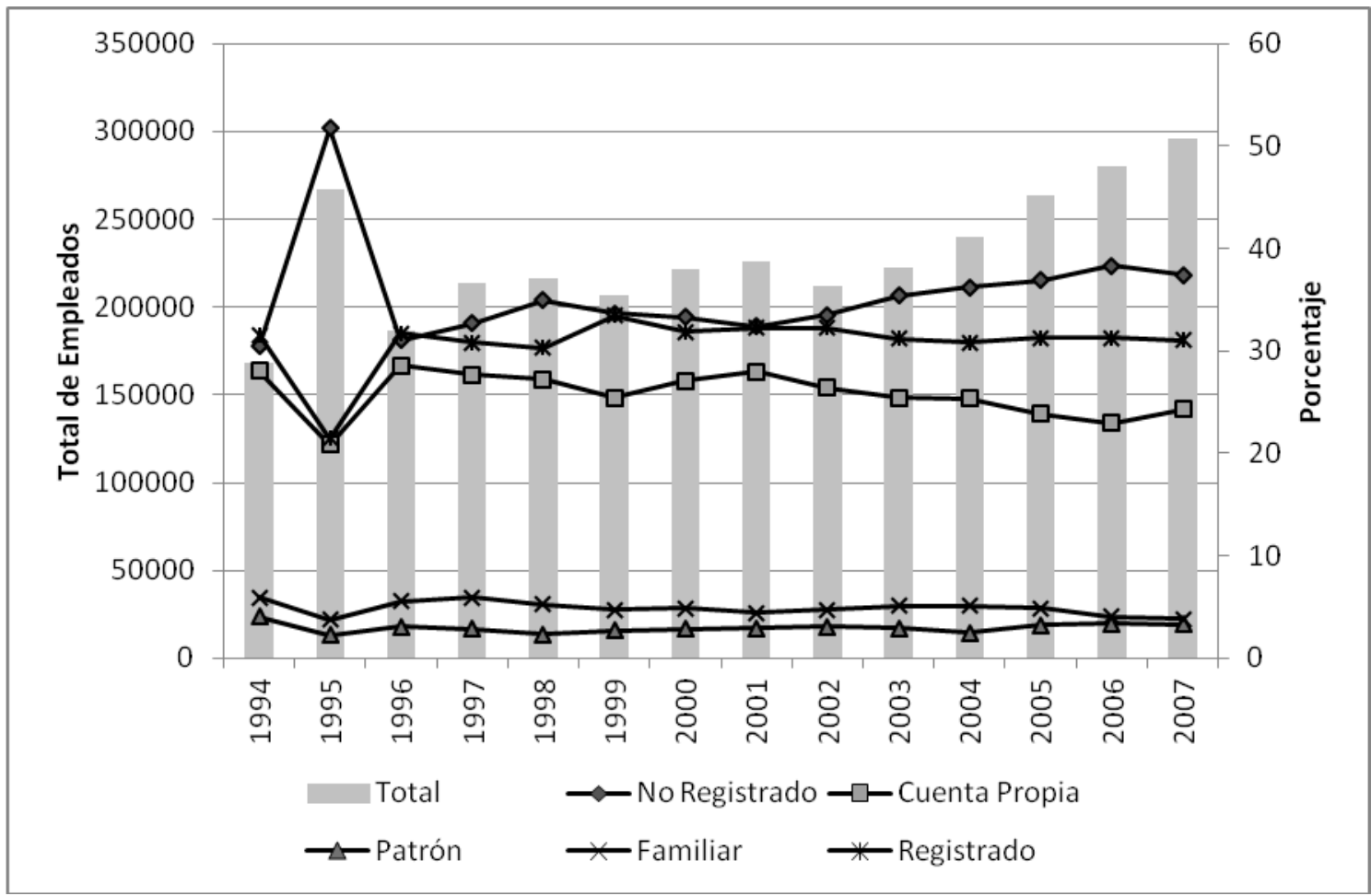

Gráfico №4: Tendencias del Empleo según categoría ocupacional de los sectores productores de bienes y servicios. Fuente: PBP, CFI, 2008. Elaboración propia

En líneas generales en el gráfico № 4 podemos observar la tendencia del mercado de trabajo hacia la informalidad, indicando que durante el período de convertibilidad los trabajadores asalariados, tanto registrados como no registrados se presentan como protagónicos en el análisis, advirtiendo la supremacía de la categoría no registrado en detrimento del empleo formal. El periodo de mayor distancia se sostiene en el año 1995 con un aumento exponencial del $50 \%$ del asalariado no registrado frente al $20 \%$ del asalariado registrado. Posteriormente al año en referencia y a lo largo del modelo de convertibilidad las tendencias entre ambas categorías comparten niveles relativamente similares en la porción de empleos no superiores al $35 \%$. Sin embargo, luego del fin de la política de paridad cambiaria, se produce un cambio de tendencia entre estas categorías de asalariados, posicionándose el empleo no registrado aproximadamente 5 puntos porcentuales por encima del registrado en todo el período de postconvertibilidad. Por otro parte el empleo por cuenta propia reviste una performance diferente. Caracterizado por tener una propensión oscilante entre un $20 \%$ y $25 \%$ del empleo a lo largo de la serie en estudio, siendo la tercera categoría más relevante de empleo en la provincia. Por lo tanto, se puede argüir que, de acuerdo a lo expuesto, no siempre los ciclos 
María Noelia Gurmendi y Rita Gabriela Salvatierra Composición y dinámica del empleo en Santiago del Estero 1994 2007

de crecimiento y expansión acompañan las tendencias con calidad en la generación de empleos.

En el gráfico subsiguiente $N^{\circ} 5$ se visibiliza la fragmentación del empleo en el sector servicios en sus diversas categorías: asalariados registrados, no registrados, cuenta propia, patrón y familiar. Se manifiesta claramente que las categorías de mayor relevancia estadística se aglutinan entre el asalariado registrado con un $45 \%$ en primer lugar, seguida del no registrado con alrededor del 25\%, es decir que ambas categorías concentran el $70 \%$ aproximadamente del empleo en dicho sector a lo largo de la serie. Las restantes categorías como cuenta propia, patrón y familiar, sumados, sostienen aproximadamente el 30\% de participación. Por lo tanto, el análisis se concentra fundamentalmente en las categorías más voluminosas y representativas que se vinculan al empleo asalariado.

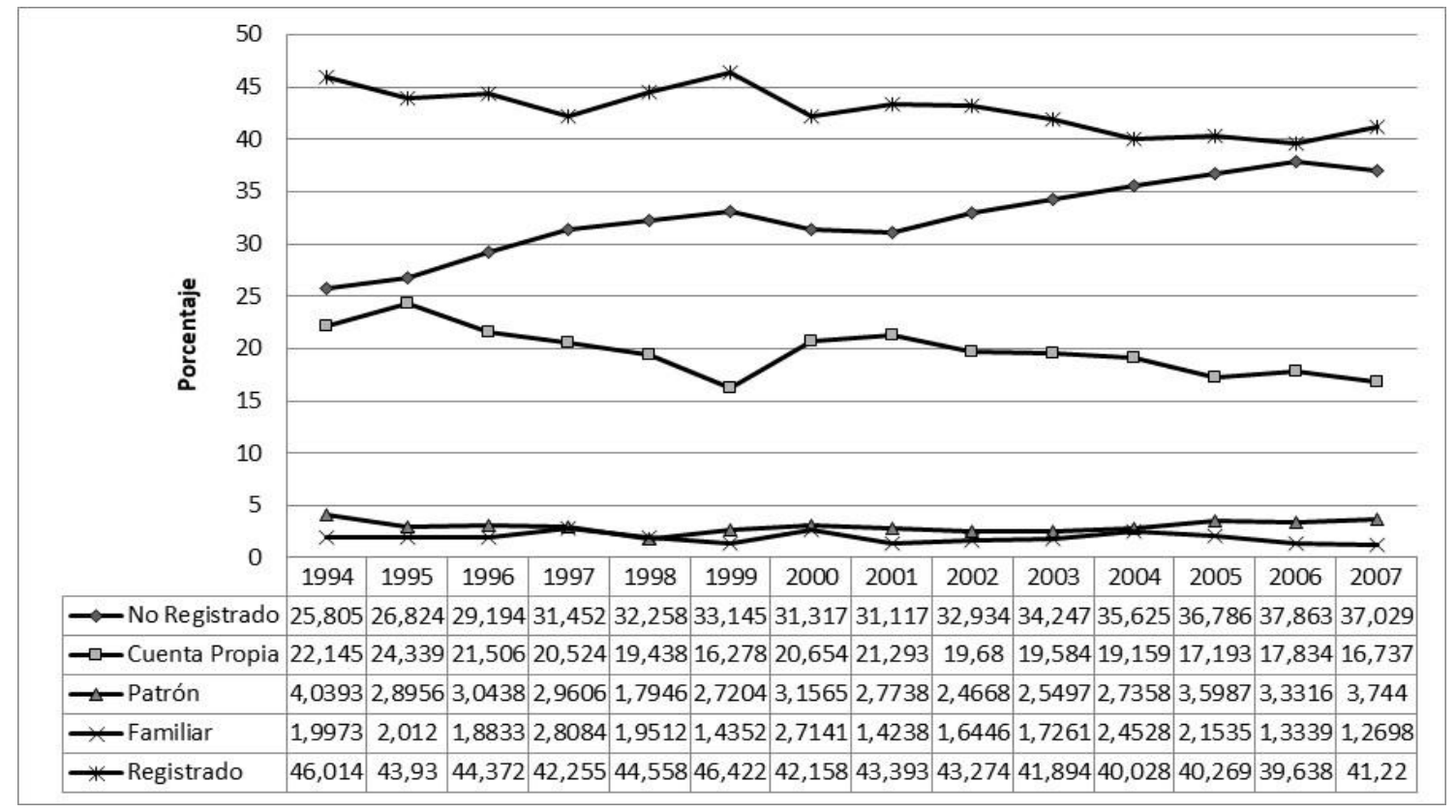

Gráfico №5: Evolución del Empleo en el sector productor de Servicios, según categorías ocupacionales. Fuente: PBP, CFI, 2008. Elaboración propia

Es necesario resaltar que el contexto político y económico se torna de gran importancia al momento de analizar la dinámica del mercado de trabajo y su nivel de institucionalidad, ya que en él pueden hallarse razones tentativas que podrían esclarecer el comportamiento del empleo. Asimismo, es fundamental comprender que la estructura productiva y el comportamiento del mercado laboral están intrínsecamente relacionados con los ciclos económicos transcurridos, ya que las referencias empíricas muestran, que de acuerdo al 
María Noelia Gurmendi y Rita Gabriela Salvatierra Composición y dinámica del empleo en Santiago del Estero 1994 2007

último ciclo expansivo (posconvertibilidad), el empleo de calidad (registrado) comienza a deteriorase con mayor pérdida de puestos de trabajo del 5\%. Mientras que la categoría de asalariado no registrado sostiene una tendencia positiva, advirtiendo que entre el periodo de convertibilidad sostenía el $25 \%$ del empleo mientras que con el derrumbe del modelo trepa a un $31 \%$ para culminar el período de análisis con un incremento del $37 \%$ junto a un ciclo expansivo de la economía. Por último, la categoría de asalariado registrado indica una tendencia a la baja en todo el periodo, con un 46\% para el año de inicio (1994) reduciendo a un 41\% para el 2007. En el interior se observa que durante la época de privatización y flexibilización del empleo (1994/2001) la mengua del trabajo formal se manifiesta más atenuada en relación al periodo considerado óptimo para la institucionalización (2002/2007) donde se registra estadísticamente la mayor precarización del empleo. Finalmente vale destacar que casi una década de crecimiento económico evidencia la persistencia y permanencia de estructuras ocupacionales fuertemente arraigadas, que pese al cambio de modelo económico no han logrado revertirse.

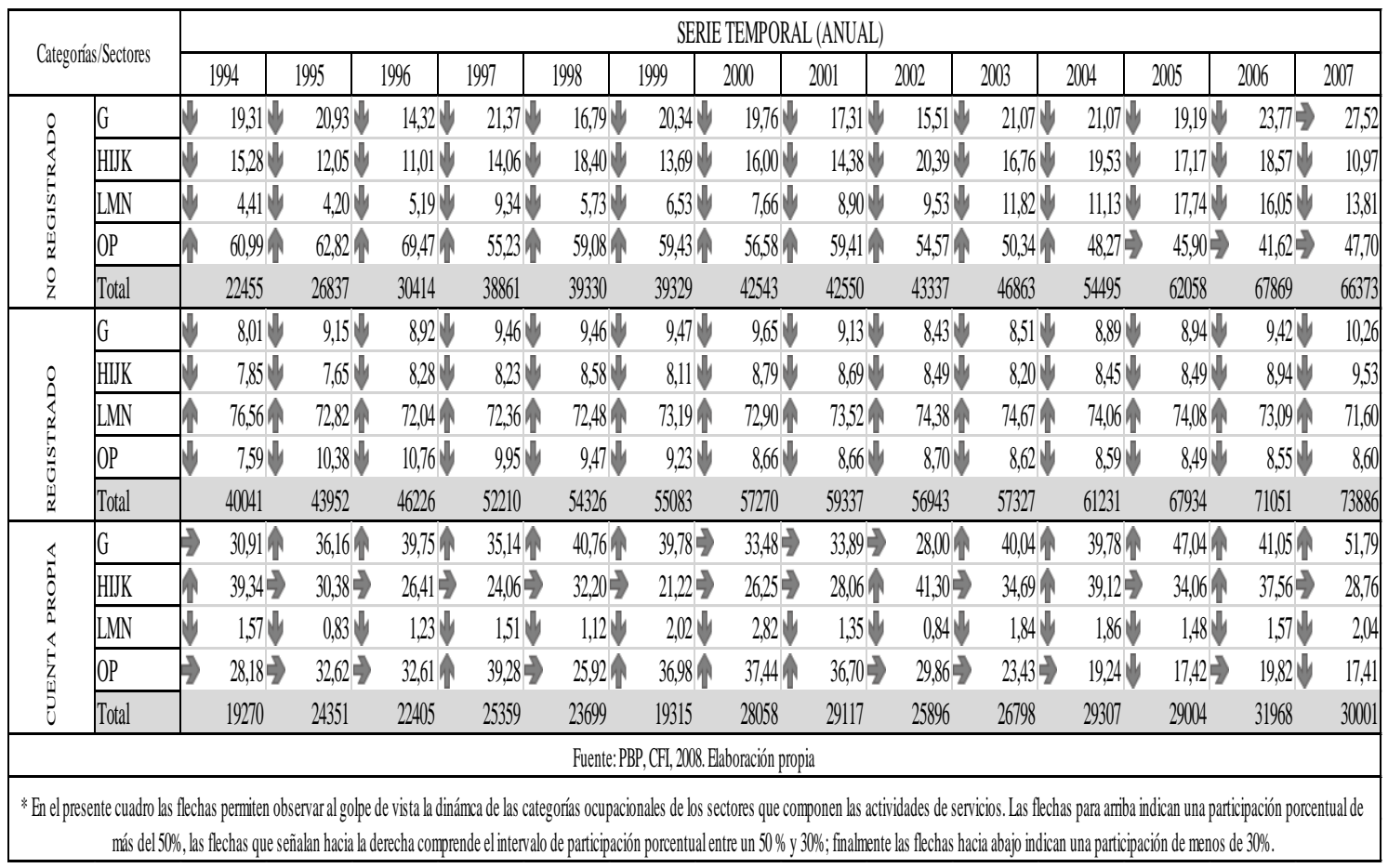

Cuadro № 1: Dinámica del Empleo según categoría ocupacional en el sector Servicios*. Fuente: PBP, CFI, 2008.

Elaboración propia

Un dato que arroja luz al presente análisis se advierte en el cuadro $\mathrm{N}^{\circ} 1$, en el cual se desagrega el nivel de participación que tuvo cada sector correspondiente a servicios. Se 
María Noelia Gurmendi y Rita Gabriela Salvatierra Composición y dinámica del empleo en Santiago del Estero 19942007

procedió a establecer un criterio metodológico comparativo de agrupamiento de los 10 sectores que intervienen en este punto (12). La lasitud del mercado laboral santiagueño, en lo que respecta a institucionalizar el empleo, se hace más visible al segmentar la categoría ocupados registrados por sector productivo, donde prevalece la supremacía del empleo público. Si observamos el agrupamiento de sectores ( $L, M, N)$ en su categoría de asalariado registrado notoriamente se advierte que aglomeran entre el $70 \%$ y $80 \%$ de empleo a lo largo del periodo. Es importante recordar que en el caso del sector salud el empleo se fracciona entre lo público y privado (esclareciendo que posee preeminencia el contrato público). Se puede argüir que la característica de estos sectores de mayor institucionalidad puede corresponderse al hecho de que es el Estado quien absorbe la fuerza de trabajo, por ende, debe garantizar, a priori, la protección y legalidad de los trabajadores. Por otro lado, los restantes sectores como $\mathrm{G}, \mathrm{H}, \mathrm{I}, \mathrm{J}, \mathrm{K}, \mathrm{O}$ y $\mathrm{P}$ contienen en su conjunto el $30 \%$ restante del empleo registrado, es decir una endeble formalidad del empleo que le corresponde al sector privado.

Un caso paradigmático de análisis merece ser examinado por el "asalariado no registrado y cuenta propia", ya que, si bien el sector servicios en su generalidad se torna eminentemente institucionalizado, al analizarlo intrasectorialmente nos devela una realidad heterogénea y desigual, donde el empleo informal y precario es comprendido por la alta participación del comercio y servicio doméstico.

A partir de lo expuesto podemos resaltar puntuales hechos estilizados para el período en análisis. Por un lado la elevada divergencia intrasectorial; en la que para el comienzo del año en estudio el asalariado registrado concentraba el $76 \%$ en $\mathrm{L}, \mathrm{M}$ y $\mathrm{N}$, en detrimento de los restantes sectores que oscilaban entre el $7 \%$ y $9 \%$, por lo tanto se advierte un proceso de dispersión de estos porcentajes a partir del año 2001, observando que tras la caída de la convertibilidad, los asalariados registrados de dicho agrupamiento $(L, M, N)$ descienden a un $72 \%$ y el empleo no registrado y cuenta propia se agudizan, iniciando la serie con el $10 \%$ y culminando con un $47 \%$ para el último año de estudio.

Otro comportamiento examinado es el creciente deterioro de la institucionalidad, con el ascenso de los asalariados no registrados y cuenta propia, que en su distanciamiento de las restantes categorías se observa la paulatina precarización. En el año 1994 el asalariado no registrado se concentraba en sectores como G (19\%), H, I, J, K (15\%) y O, P (60\%), para alcanzar el pico máximo en el último año en estudio. Contrariamente el periodo de mayor volatilidad del empleo no registrado estuvo acompañado de un proceso de recuperación económica; por lo tanto, se observa que la creciente brecha a favor del trabajo no registrado 
María Noelia Gurmendi y Rita Gabriela Salvatierra Composición y dinámica del empleo en Santiago del Estero 19942007

no se originaría en la década neoliberal de los '90, paradigma del modelo de mercado y de la flexibilización laboral, sino justamente a partir de su caída en el año 2002.

Es prioritario destacar que en el caso del sector servicios básicos es el Estado el garante de los derechos laborales, por lo que resulta paradójico que el empleo tenga una tendencia a la des-institucionalización del trabajo bajo características de desprotección, inestabilidad, polivalencia funcional y bajos ingresos.

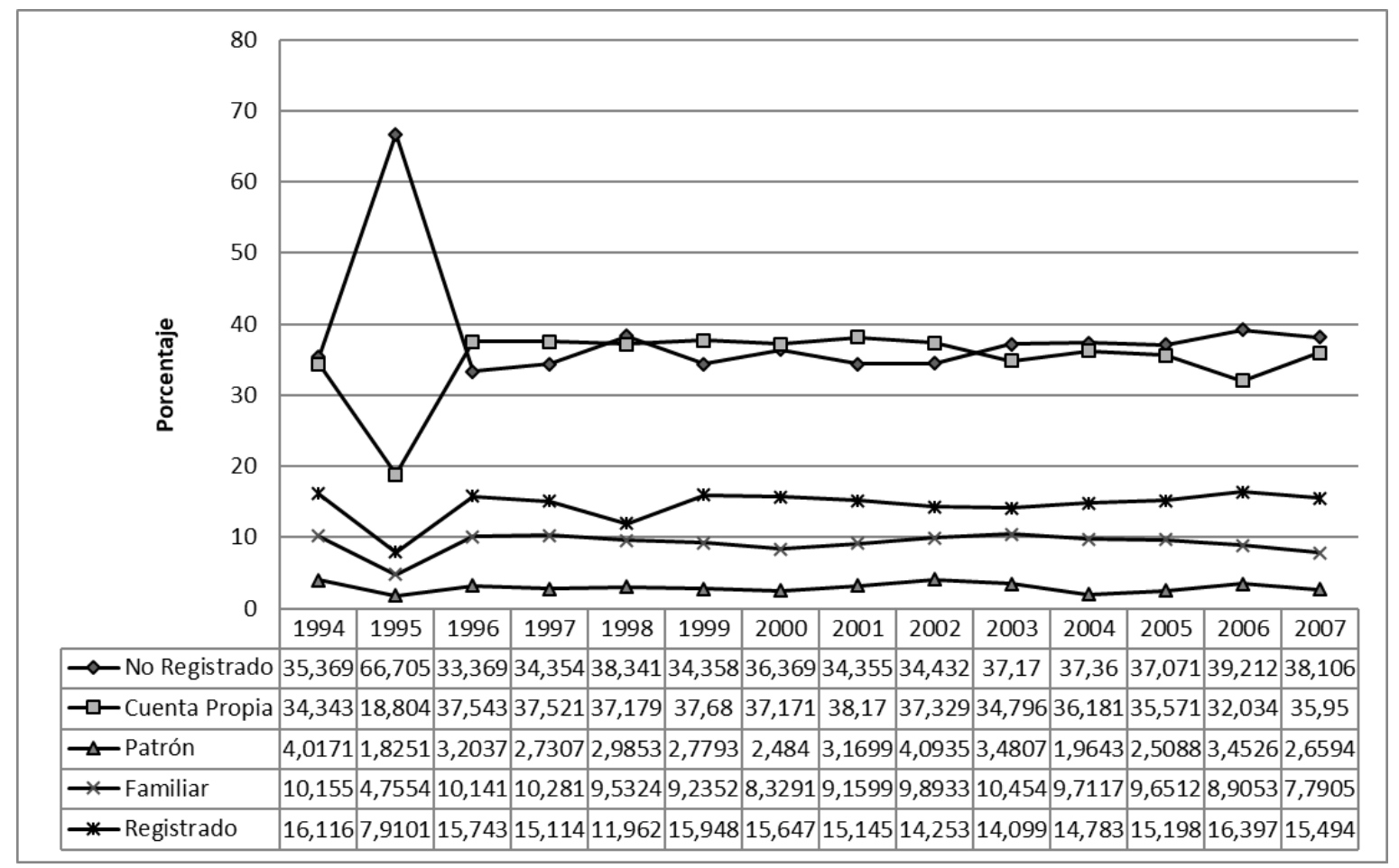

Gráfico № 6: Evolución del Empleo en el sector productor de Bienes, según categorías ocupacionales. Fuente: PBP, CFI, 2008. Elaboración propia

En el gráfico № 6 se puede apreciar que el sector productor de bienes ostenta una elevada incidencia de la informalidad, teniendo como principales categorías al asalariado no registrado y cuenta propia. Ambas oscilan entre un $30 \%$ y $40 \%$ del total de empleo, siendo relevante que en el año 1995 el asalariado no registrado trepa exponencialmente al 66,7\% constituyéndose en una categoría permanente de los sectores productores de bienes. Al mismo tiempo el comportamiento del cuentapropismo manifiesta su mayor contracción en el año de auge que registra el empleo informal (1995), observándose una caída del 18,8\%, siendo la segunda categoría más importante del total de empleo.

Párrafo aparte merece la performance que ha tenido el empleo registrado en toda la serie. Tomando en cuenta la tendencia estable y minoritaria de su participación en dicho sector. Esta 
María Noelia Gurmendi y Rita Gabriela Salvatierra Composición y dinámica del empleo en Santiago del Estero 19942007

categoría registra un máximo del 16\% y una caída del $7 \%$ entre los años en estudio. Claramente se advierte un comportamiento tendiente a la informalidad en detrimento de la institucionalización, lo que muestra que no siempre el crecimiento económico es acompañado de formalidad del empleo. Es preciso remarcar que, pese a que a nivel nacional se sancionaron una cantidad de leyes laborales tendientes a la protección, estabilidad y formalidad, dichas políticas no han tenido los resultados esperados a nivel provincial, ni mucho menos han conseguido mitigar el impacto que ha generado la incorporación de innovaciones tecnológicas en el sector de bienes predominante, es decir el sector agrícola ganadero.

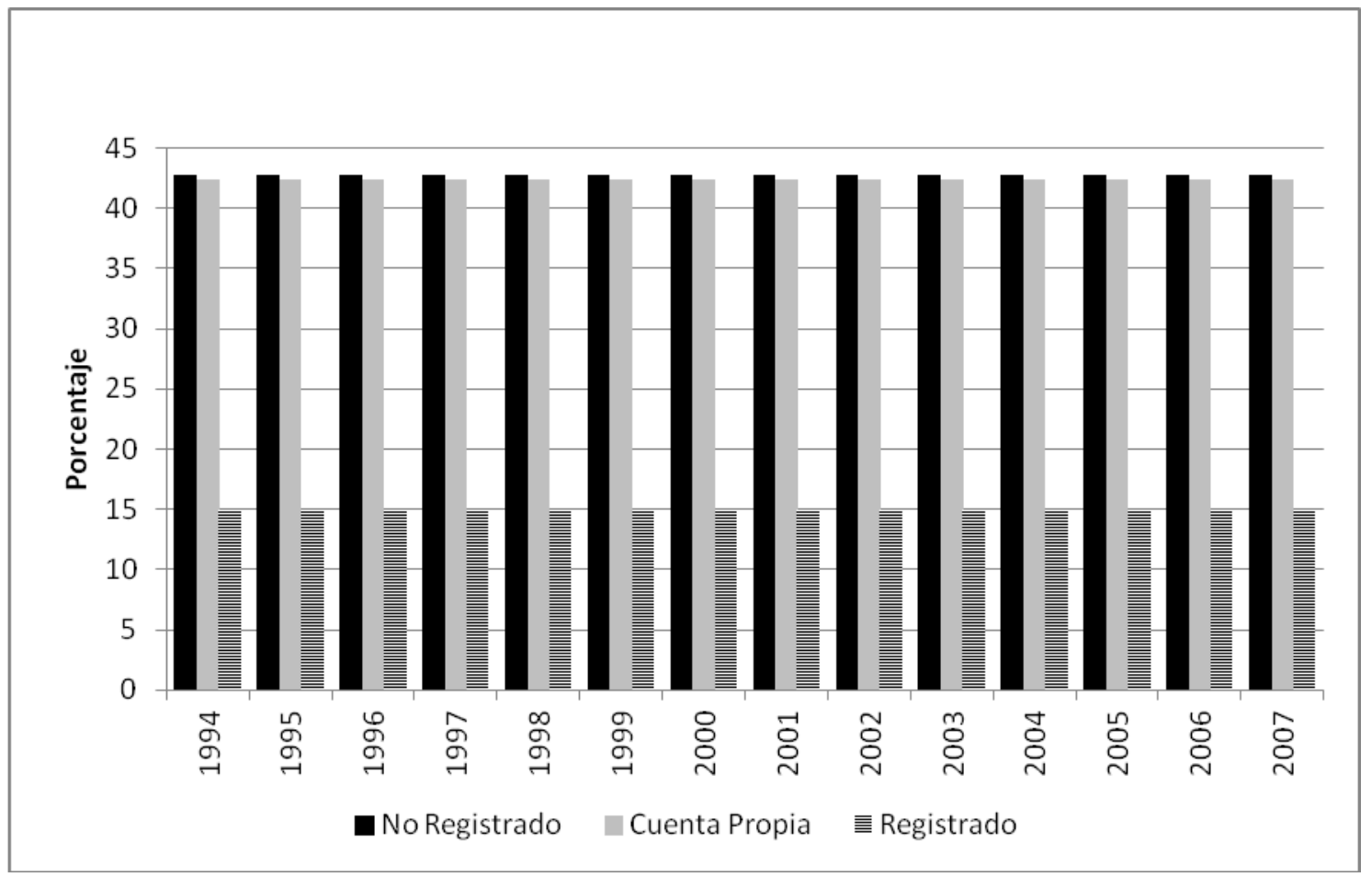

Gráfico № 6-A: Categorías ocupacionales en el sector A. Fuente: PBP, CFI, 2008. Elaboración propia.

El gráfico № 6-A, ilustra que la categoría no registrado y cuenta propia son ostensiblemente superiores al empleo registrado en todo el período en el sector (A). Esto podría estar vinculado a dos razones; la primera de ellas refiere al escaso dinamismo productivo y tecnológico del sector tradicional agrario, donde la profesionalización de la agricultura tiene por finalidad elevar la capacidad y competitividad productiva; y por otro lado a la elevada intensidad de capital por unidad producida (13), traduciéndose en la baja absorción de mano de obra asalariada con un alto porcentaje de trabajo informal condicionando a la baja los salarios de la economía regional. Por lo tanto, este sector ha continuado con su tendencia histórica caracterizada por expulsar mano de obra, proceso que está relacionado con las actividades de subsistencia de baja 
María Noelia Gurmendi y Rita Gabriela Salvatierra Composición y dinámica del empleo en Santiago del Estero 19942007

productividad en la que parte de la producción es para el consumo familiar y el restante para la venta en el mercado zonal o local.

En Santiago del Estero este reciente esquema productivo ha visibilizado las asimetrías productivas en el sector empresarial agrario, ya que las tecnologías agrícolas no han sido absorbidas, desarrolladas o distribuidas simétricamente en su plenitud. Estas asimetrías podrían estar relacionadas con la tenencia de la tierra que condiciona la forma de su uso, la falta de oferta de mano de obra calificada según zona o área productiva, y las inversiones a largo o corto plazo (Salvatierra y Vargas, 2015).

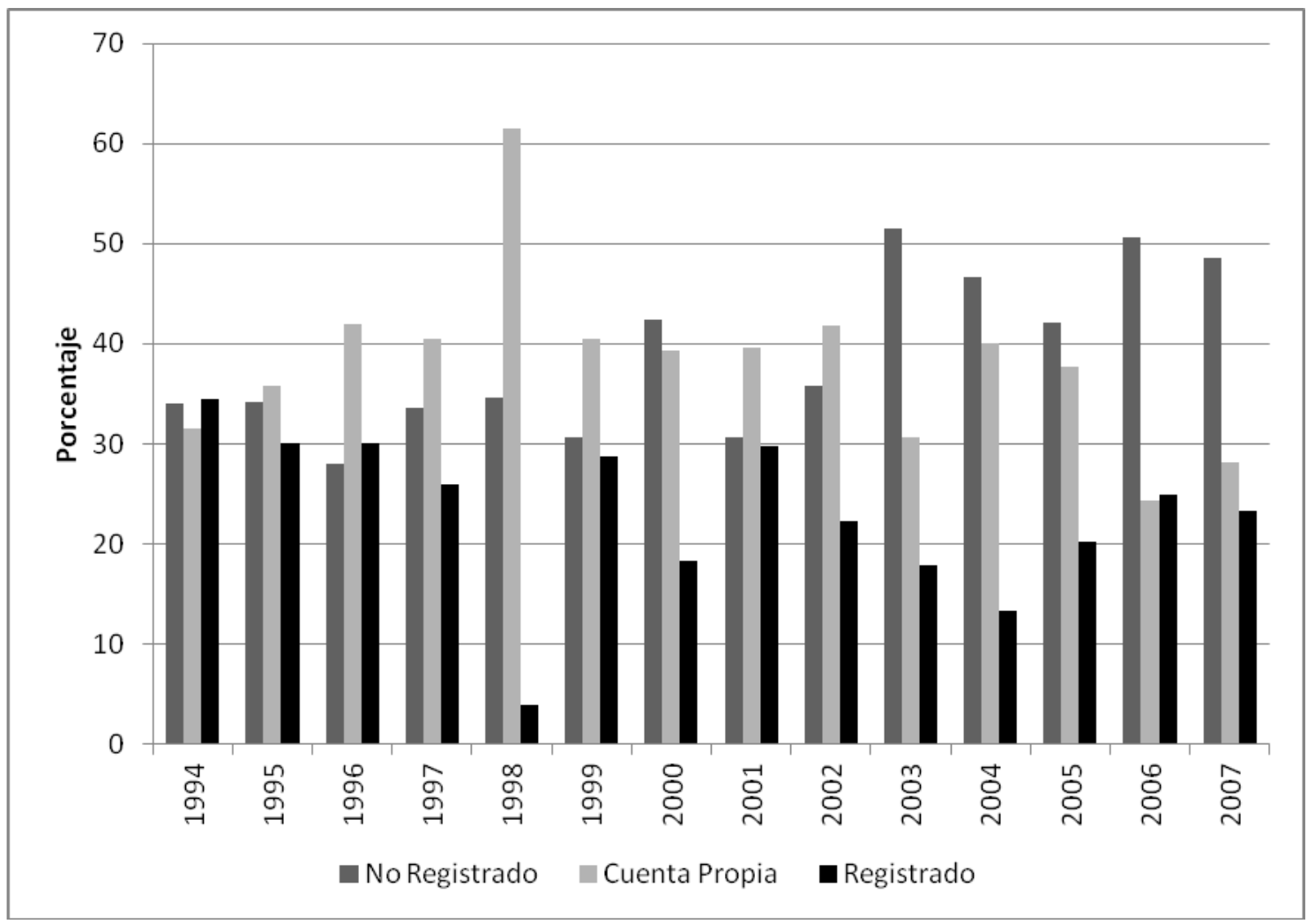

Gráfico №6-B: Categorías ocupacionales en el Sector D. Fuente: PBP, CFI, 2008. Elaboración propia

En lo que respecta al sector industrial (D), en el gráfico 6-B se muestra que la evolución de sus categorías más relevantes reproduce el esquema de comportamiento general del total de los sectores productores de bienes en cuanto a la elevada informalidad, siendo las más representativas el asalariado no registrado y cuenta propia. Del mismo modo el empleo registrado imita la performance notoriamente negativa en todo el período de análisis. Esta situación de elevada informalidad en el sector industrial puede explicarse por diversos factores; es plausible que una de ellas se vincule con una razón microeconómica, donde la poca 
María Noelia Gurmendi y Rita Gabriela Salvatierra Composición y dinámica del empleo en Santiago del Estero 1994 2007

presencia de establecimientos fabriles de mayor tamaño y/o de economías de escala dinámicas ligadas a la innovación tecnológica y a los procesos de aprendizaje de nuevas técnicas productivas influyen en la capacidad de aprovechamiento de las externalidades vinculadas a una competitividad genuina, que en términos de F. Fajnzylber (1988), refiere a factores como la eficiencia productiva, diferenciación y versatilidad del bien manufacturado, redes de comercialización, capacidad de financiamiento y sostenibilidad.

Por otro lado, es posible pensar también en una razón macroeconómica que contribuyó en dicho proceso, donde luego de la fuerte devaluación del tipo de cambio vigente 2001/02 la transferencia de recursos a los sectores productores de bienes, principalmente de bienes básicos en Santiago del Estero, ha generado un contexto de reprimarización de la economía, que se basa en el auge de los productos básicos estandarizados (commodities) a raíz de la mejora de los términos de intercambio en favor de los exportadores de bienes intensivos en recursos naturales en detrimento de la inversión en sectores industriales. Desde esta perspectiva, los ciclos económicos no sólo afectan al número de puestos de trabajo que se generan, sino también a su calidad, forjando profundas huellas de desigualdad social.

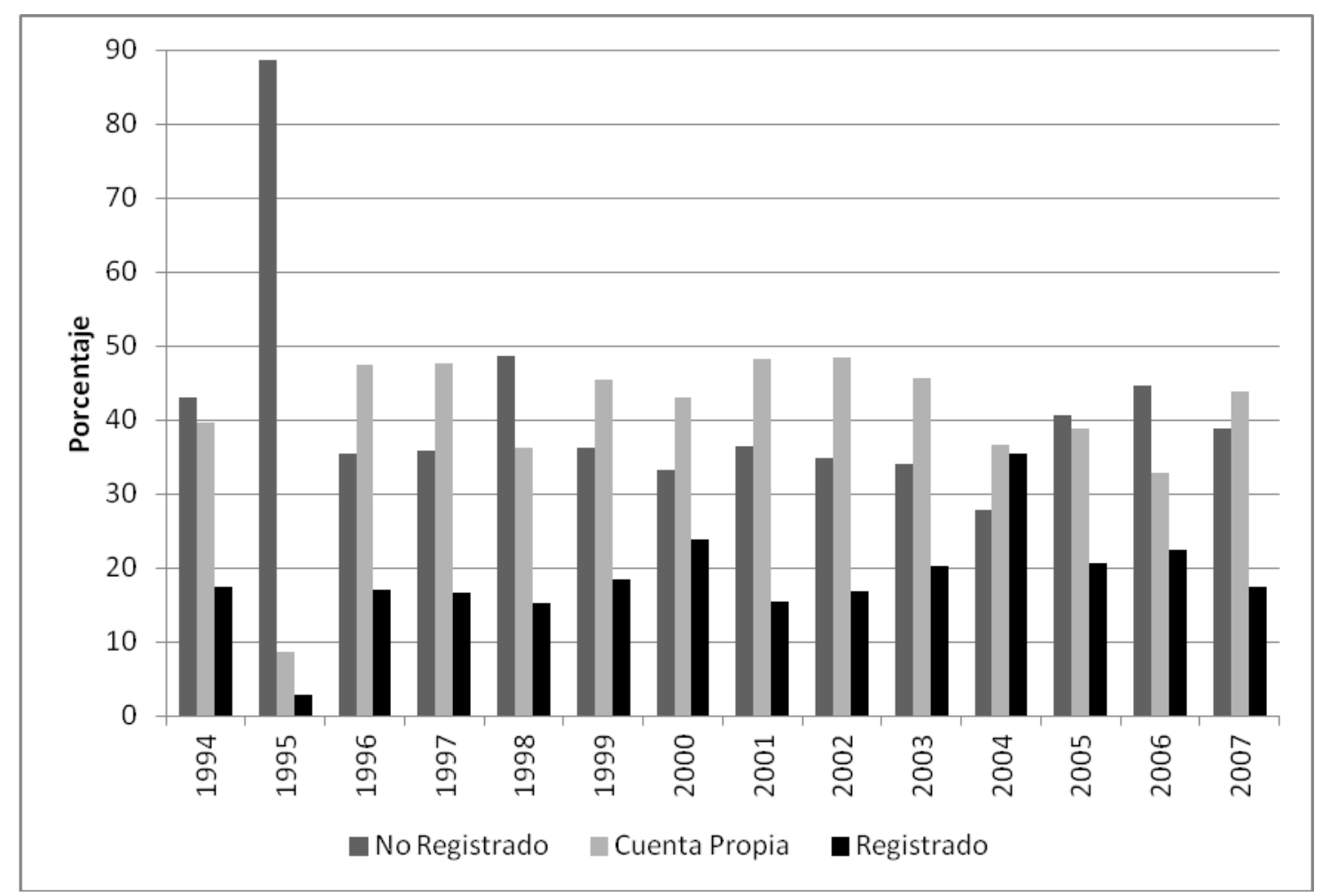

Gráfico № 6-C: Categorías ocupacionales en el Sector F. Fuente: PBP, CFI, 2008. Elaboración propia 
María Noelia Gurmendi y Rita Gabriela Salvatierra Composición y dinámica del empleo en Santiago del Estero 19942007

Comparativamente en el sector de la construcción ( $F$ ) (véase gráfico № 6-C)se observa la predominancia de la categorías ocupacionales informales, tanto los trabajadores por cuenta propia como los no registrados a lo largo del periodo en estudio muestran un comportamiento oscilante entre el 30\% y 43\% aproximadamente, excepto en el año 1995 que el trabajo no registrado tuvo un pico del $80 \%$, para luego posicionarse como la segunda categoría más relevante hasta los años 2005/2006 presumiéndose una transferencia de trabajadores de la categoría cuenta propia a no registrado, para nuevamente ocupar el segundo puesto en el 2007. La categoría de asalariado registrado tiene un comportamiento visiblemente negativo, similar al resto de los sectores productores de bienes en casi todo el período analizado. El elevado nivel del cuentapropismo en este sector podría vincularse al hecho de que refieren a un conjunto de trabajadores autónomos y pequeños emprendedores que encuentran en la construcción una actividad económica de subsistencia, siendo particularmente visible en los trabajadores que tienen menores niveles de cualificación y capacitación.

\section{Reflexiones finales}

A partir de lo expuesto es necesarios remarcar, que el mercado de trabajo representa un eslabón fundamental para el desarrollo. En él se expresan las fuerzas productivas emergentes de las peculiaridades de su estructura sectorial, tanto como los rasgos plurales de su política. Así también, el empleo tiene un enorme peso en la configuración social. Factores políticos, institucionales, se entrecruzan, definen y se definen, en este ámbito, vitales para determinar los factores que inciden en el desarrollo económico y que caracterizan la estructura productiva.

La principal fuente laboral de la provincia a lo largo del periodo, se concentra en el sector servicios, donde gravita con mayor importancia el Estado como principal empleador, al mismo tiempo que el resto de las actividades de servicios -informales- se vinculan entre si tornandose en una relacion de plena dependencia donde la empleo publico condiciona la dinamica de las actividades comerciales, de servicio domestico, enseñanza y salud entre otros.

Se percibe una progresiva y clara tendencia a la precarización e informalidad del empleo, más significativo en el sector de bienes (agropecuario e industrial) en todo el periodo, donde comienza a imitar el mismo comportamiento el sector servicios. Esta situación, tiene una marcada propensión de alza en la etapa de la post-convertibilidad, demostrando que, no siempre se da la relación positiva entre crecimiento económico, generación y calidad del empleo. Este panorama representa un círculo vicioso de ajuste defensivo, caracterizado por el bajo o nulo crecimiento de la productividad, la lasitud de actividades dinámicas de alta competitividad y por lo tanto en una exigua apertura a un cambio estructural virtuoso que incide 
María Noelia Gurmendi y Rita Gabriela Salvatierra Composición y dinámica del empleo en Santiago del Estero 19942007

directamente en el mercado de trabajo y su institucionalidad, donde las actividades de servicios se conforman como un sustituto irremediable de la expulsión de mano de obra del sector tradicional bajo un tipo de subsistencia informal.

Finalmente, la estructura del empleo provincial posee características muy similares a lo que sucede tanto a nivel nacional como global, referido al hecho de que el sector servicios tiene mayor preponderancia. Sin embargo, el paso de una sociedad industrial a una posindustrial en los países desarrollados, responde al hecho de que, en la medida que la sociedad se vuelve más desarrollada comienza a demandar servicios especializados que crecen en difusión y sofisticación con la riqueza de la sociedad, por lo tanto, el sector se manifiesta eficiente y altamente productivo. En cambio, Santiago del Estero constituye una región marginal del capitalismo periférico, con una matriz productiva incapaz de sostener el aumento de la oferta de trabajo, dado que la industria nunca logró desarrollarse, con actividades dependientes e inestables con alta precariedad, baja productividad y escaso dinamismo.

\section{Notas}

(1) El PBG es el indicador básico del crecimiento económico de una región, en tanto que es el indicador macroeconómico global más importante para medir la situación y evolución económica e identificar los elementos que definen una estructura económica y productiva (G. Sereno; J. Silveti; J. Antuña ; C. Cantos, 2007- Consejo Federal de Inversiones).

(2) Cabe destacar que esa heterogeneidad como característica del mercado de trabajo, fue forjándose luego del quiebre del modelo agroexportador, durante la década denominada "infame" de 1930, y que gradualmente se fue consolidando, en el marco de un sistema semiindustrial dependiente (Llach, 1987).

(3) Este concepto alude a todos aquellos bienes que se pueden consumir dentro de la economía que los produce, y se pueden exportar e importar. Es decir, son aquellos bienes que son susceptibles de ser comercializados o vendidos internacionalmente.

(4) El salario real será aquel que representa la cantidad de bienes que el trabajador podrá adquirir con el volumen de dinero que percibe y por tanto representa el poder adquisitivo, su poder de compra, la cantidad de bienes y servicios que podrá lograr a partir de su salario.

(5)Los sectores productores de bienes están integrados por: A). Agricultura, ganadería, caza y silvicultura; C). Explotaciones de Minas y canteras; D). Industria manufacturera; E). Suministro de electricidad, gas y agua; F). Construcción. Asimismo, los sectores productores de servicios lo comprenden: G). Comercio y reparaciones; H). Hoteles y restaurantes; I). Transporte, almacenamiento; J). Intermediación financiera; K). Actividades inmobiliarias, empresariales y de alquiler; L). Administración pública, defensa y seguridad social obligatoria; M). Enseñanza; N). Salud; O). Otras actividades de servicios; y P). Hogares privados con servicio doméstico. Por otra parte, omite el sector B compuesto por actividades pesqueras, dado que 
María Noelia Gurmendi y Rita Gabriela Salvatierra Composición y dinámica del empleo en Santiago del Estero 19942007

su representación es tanto en productividad, producción y generación de ingresos es extremadamente ínfima.

(6) Entre las diversas explicaciones del estancamiento del sector agrícola-ganadero algunos autores como Díaz (1975) señalan que este hecho fue la respuesta a la reducción de los niveles de rentabilidad asociada con las retenciones y/u otras formas de distorsiones sobre los precios del mercado. Mientras que otros autores como Giberti, 1964; Braun, 1974; Flichmann, 1977; sostienen que este fenómeno responde a una estructura productiva caracterizada por la concentración de tierras que permiten comportamientos conservadores frente a las señales de precios del mercado". (Bisang, 2007 p. 188).

(7) La terciarización implica el paso de una estructura social/económica industrial a una post-industrial o de servicios propia de los países desarrollados, donde el sector terciario es el responsable de la organización, dirección, control y desarrollo de toda actividad humana dirigida al funcionamiento de la sociedad y del aparato productivo. Por lo tanto, se convierte en el sector económico que mayor cantidad de empleo absorbe (Bell, 1973). En el caso santiagueño, es sustitutiva ya que el excedente de oferta laboral como consecuencia de la expulsión de mano de obra del sector rural, presiona a la demanda de trabajo del sector servicios, quien sustituye a la industria en la absorción de trabajo y como consecuencia de ello se genera empleo de baja productividad y bajos salarios.

(8) En progreso técnico (CEPAL,2007), se trabaja la categoría de subsistencia informal para definir una sociedad con altos niveles de desigualdad, heterogeneidad estructural donde predominan los servicios de baja productividad y competitividad en el marco de una terciarización sustitutiva, idea que priori resulta consistente para explicar la particularidad de la dinámica del mercado de trabajo santiagueño.

(9) La provincia posee una economía con una dinámica limitada, basada en una estructura productiva tradicional con escasa innovación, que a su vez conserva un modelo dual productivo, donde coexisten de dos sectores de producción de enclaves diferenciados, Por un lado un sector agro-ganadero empresarial cuyas particularidades le permiten ingresar y operar en el mercado formal y otro sector rezagado-de producción tradicional- caracterizado por la escasa capitalización, precariedad y los bajos ingresos de actividades rezagadas.

(10) Para ampliar Véase CEPAL (2014), "Pactos para la igualdad. Hacia un futuro sostenible" al mundo del trabajo como la llave maestra para la igualdad.

(11) Es preciso tener en cuenta que se considera sector informal a los trabajadores independientes no calificados, los trabajadores no remunerados, los propietarios y los asalariados de microempresas (con exclusión de trabajadores calificados) y los trabajadores del servicio doméstico (CEPAL, 2012).

(12) El criterio se sostuvo por la relevancia estadística que presentan los mismos, donde algunos sectores poseen una misérrima contribución porcentual particular, como el caso de $\mathrm{H}, \mathrm{I}, \mathrm{J}, \mathrm{K}$ y por otro lado aquellos con un mayor nivel de participación como L, M, N, comparten entre si el hecho de que gravita con mayor importancia el empleo público y /o una transferencia del Estado. Asimismo, los sectores $\mathrm{O}$ y $\mathrm{P}$, se agrupan porque ambos acompañan una sostenida precariedad. Por otro lado, se analiza de manera particular el sector estrella referido a comercio $(G)$ debido a que el mismo inviste un alto caudal de empleo.

Question, Vol. 1, N. ${ }^{\circ}$ 64, octubre-diciembre 2019. ISSN 1669-6581

Instituto de Investigaciones en Comunicación | Facultad de Periodismo y Comunicación Social | Universidad Nacional de La Plata La Plata | Buenos Aires | Argentina

Página 20 de 22 
María Noelia Gurmendi y Rita Gabriela Salvatierra Composición y dinámica del empleo en Santiago del Estero 19942007

(13) El sector agrícola redujo el coeficiente de utilización de mano de obra produciendo una recomposición del empleo hacia formas más precarias en el sector moderno exportador, observándose una reducción relativa del empleo en las unidades productivas tradicionales.

\section{Bibliografía}

Argentina. Consejo Federal de Inversiones. Dirección general de Estadísticas y censos del Santiago del Estero (2008). Producto Bruto Geográfico en la Provincia de Santiago deL Estero. Tercer informe de actividades. Segunda Etapa (1994/2207). Santiago del Estero: Dirección general de Estadísticas y censos de Santiago del Estero.

Bell, D. (1973). El advenimiento de la sociedad posindustrial. Ed. Ariel. Barcelona: España.

Bisang, Roberto (2007). "El desarrollo agropecuario en las últimas décadas: ¿volver a creer?”. En Kosacoff, Bernardo (ed.) Crisis, recuperación u nuevos dilemas. La economía argentina 2002 - 2007 (pp. 187-260). Buenos Aires: CEPAL, Naciones Unidas.

Chile. Comisión Económica para América Latina y el Caribe (CEPAL) (2007). Progreso técnico y cambio estructural en América Latina. Santiago de Chile: CEPAL.

Chile. Comisión Económica para América Latina y el Caribe (CEPAL) (2014). Pactos para la igualdad. Hacia un futuro sostenible. Santiago de Chile: CEPAL.

Chile. Comisión Económica para América Latina y el Caribe (CEPAL) (2012). Cambio estructural para la igualdad. Una visión integrada el desarrollo. Santiago de Chile: CEPAL.

Fajnzylber, F. (1988). "Competitividad internacional, evolución y lecciones". Revista CEPAL (36), 7-24.

Forni Floreal (1991), "Empleo, Estrategias de vida y Reproducción”. Hogares rurales en Santiago del Estero. CEIL

Salvatierra, Rita G. y Vargas Fabricio I. (2015). Una aproximación al análisis de las asimetrías en la estructura productiva agrícola de Santiago del Estero. Libro de Trabajo XIII Jornadas Regionales de Economía y Sociedad del NOA. Jujuy: ARESNOA

Salvia, Agustín (2003). "Los trabajadores y el trabajo en crisis". $6^{\circ}$ Congreso Nacional de estudios del trabajo. Buenos Aires.

Schokolnik, Mariana (2008), "Los desafíos de la medición del empleo y el desempleo en la globalización, CEPAL.

Schumpeter, Joseph (1963) "Teoría del desenvolvimiento económico" $3^{\circ}$ edición. Fondo de Cultura Económica, Méjico. 
Silveti, Jorge L.; Gurmendi, Noelia y Salvatierra, Rita G. (2017). "Cambio estructural y desarrollo productivo en Santiago del Estero. Periodo 1994/2007". Trabajo y Sociedad. (19), 377-390.

Tasso Alberto y Zurita Carlos, (2013) "Aves de paso. Los trabajadores estacionales en Santiago del Estero". Trabajo y Sociedad, №21.

Zurita Carlos, (1997) "El empleo tradicional en el área tradicional de la Argentina. Marcos demográficos, análisis de la subutilización y políticas de empleo en Santiago del Estero". Estudios sociológicos. Volumen XV, №44.

Zurita Carlos, (1999) "El trabajo en una sociedad tradicional. Estudios sobre Santiago del Estero". Ediciones CICYT-UNSE. 